\title{
Reconstruction of erythemal UV-doses for two stations in Austria: a comparison between alpine and urban regions
}

\author{
H. E. Rieder ${ }^{1,2, *}$, F. Holawe ${ }^{2}$, S. Simic ${ }^{1}$, M. Blumthaler ${ }^{3}$, J. W. Krzyścin ${ }^{4}$, J. E. Wagner ${ }^{1}$, A. W. Schmalwieser ${ }^{5}$, and \\ P. Weihs ${ }^{1}$ \\ ${ }^{1}$ Institute for Meteorology, University of Natural Resources and Applied Life Sciences (BOKU), Vienna, Austria \\ ${ }^{2}$ Institute for Geography and Regional Research, University of Vienna, Vienna, Austria \\ ${ }^{3}$ Division for Biomedical Physics, Innsbruck Medical University, Innsbruck, Austria \\ ${ }^{4}$ Institute of Geophysics, Polish Academy of Sciences, Warsaw, Poland \\ ${ }^{5}$ Institute of Medical Physics and Biostatistics, University of Veterinary Medicine Vienna, Vienna, Austria \\ * now at: Institute for Atmospheric and Climate Science, ETH Zurich, Zurich, Switzerland
}

Received: 7 December 2007 - Published in Atmos. Chem. Phys. Discuss.: 21 January 2008

Revised: 3 September 2008 - Accepted: 15 September 2008 - Published: 31 October 2008

\begin{abstract}
The aim of this study is the reconstruction of past UV-doses for two stations in Austria, Hoher Sonnblick and Vienna, using a physical radiation transfer model. The method uses the modeled UV-dose under clear-sky conditions, cloud modification factors and a correction factor as input variables. To identify the influence of temporal resolution of input data and modification factors, an ensemble of four different modelling approaches was calculated, each with hourly or daily resolution. This is especially important because we found no other study describing the influence of the temporal resolution of input data on model performance. Following the results of the statistical analysis of the evaluation period the model with the highest temporal resolution (HMC) was chosen for the reconstruction of UV-doses. A good agreement between modelled and measured values of erythemally effective UV-doses was found at both stations. In relation to the reference period 1976-1985 an increase in the erythemal UV-dose in Vienna of $11 \%$ is visible in the period 1986-1995 and an increase of 17\% in the period 19962005 can be seen. At Hoher Sonnblick the corresponding increase is $2 \%$ and $9 \%$. For the different seasons the strongest increase in erythemal UV-dose has been found for winter and spring season at both stations. Further the influences of total ozone and cloudiness on changes in erythemal UV-doses were analyzed. This analysis showed for both stations, that changes in total ozone had a larger influence on erythemal UV-doses than changes in cloudiness.
\end{abstract}

Correspondence to: H. E. Rieder (harald.rieder@env.ethz.ch)

\section{Introduction}

Since the detection of the Antarctic ozone hole in the early 1970s (e.g. Farman et al., 1985; Stolarski et al., 1991; Gleason et al., 1993) the interest in solar UV-B increased within the scientific community and the general public because of the link between reduced ozone concentrations and increased UV radiation doses (e.g. Calbó et al., 2005). The UV part of the solar spectrum covers only a small part of the total energy of solar radiation, but its importance is explained by the high energy of the photons in this wavelength range (e.g. Gantner et al., 2000). Solar UV radiation covers the wavelength range of $200-400 \mathrm{~nm}$ and is subdivided in three spectral regions known as UV-C (200-280 nm), UV-B (280-315 nm) and UV-A (315-400 nm). The boundary between UV-A and UV-B is not clearly fixed, but most international agencies and consortia agree establishing the boundary at $315 \mathrm{~nm}$ (World Health Organization, 2002; European Union's action COST 713 (Vanicek et al., 2000); Commission Internationale de l'Eclairage, 1999; International Agency for research on Cancer, 1992).

Clouds, solar zenith angle and total ozone amount are the most important factors influencing UV radiation at ground levels (e.g. Burrows, 1997; Kerr, 2003). Stratospheric ozone is especially important because it is the major atmospheric absorber of solar UV-B radiation (e.g. UNEP, 1998; Matthijsen et al., 2000).

Long-term measurements of UV radiation are rare and datasets are only available for some locations. Also most of these measurements do not provide spectral information on the UV part of the spectra. Knowledge of past UV radiation

Published by Copernicus Publications on behalf of the European Geosciences Union. 
levels is of increasing interest in order to estimate long-term biological effects (e.g. Reuder and Koepke, 2005). An increase in UV-doses may lead to a broad variety of environmental and health effects (e.g. Slaper et al., 1996; UNEP, 1998; National Radiological Protection Board, 2002). The eye, the immune system and the skin are the three major organ systems of humans which are commonly exposed to sunlight and for all of them health effects regarding solar UV radiation have been documented (WHO, 1994, 2006; Longstreth et al., 1998). Among the most important biological effects of UV radiation are the development of skin cancer, pigmentation and erythema, aging effects and diseases related to the eyes like photokeratitis and photoconjunctivity. The erythema is probably the most widely experienced form of acute solar injury to the skin (Longstreth et al., 1998). Further various epidemiological studies have addressed the relative contributions of UV radiation to photocarciogenesis, in particular with regard to the development of melanoma (Setlow, 1974; Moan et al., 1999; Woodhead et al., 1999). A decrease in global ozone concentration of about 10 percent would lead to an increase in skin cancer cases of 300000 per year (IPCS, 1994). Climate Change may also have an effect on future UV radiation doses reaching the earth's surface through changes in cloud amount, cloud properties and surface albedo (e.g. Lindfors and Vuilleumier, 2005).

Increased research activities in the field of UV radiation have led in the last years to worldwide monitoring of UV radiation levels (e.g. Seckmeyer et al., 1995), a better understanding of the atmospheric processes that influence the UV part of the spectra (e.g. Schwander et al., 1997; Weihs and Webb, 1997a, b) and the development of modelling approaches for the reconstruction of past UV radiation levels (e.g. Kaurola et al., 2000; Gantner et al., 2000; Lindfors and Vuilleumier, 2005; Reuder and Koepke, 2005).

Recent studies have shown that models may be able to reconstruct past UV-doses with an accuracy between 5 and 15 percent (Kaurola et al., 2000; Fioletov et al., 2001; Reuder and Koepke, 2005). Most of these models were based on daily input data. A few studies however already use hourly meteorological input data (Den Outer et al., 2005; Reuder and Koepke, 2005). The exact improvement in accuracy by using hourly data has however not really been investigated. Only a few studies have given a statement on the exact magnitude of the influence of the model input factors influencing reconstructed UV-doses (e.g. Reuder and Koepke, 2005; Lindfors and Vuilleumier, 2005).

During the last decade reconstruction studies for several regions in Europe, especially in Nordic and central European countries, were performed (e.g. Lindfors et al., 2003; Den Outer et al., 2005; Lindfors and Vuilleumier, 2005; Reuder and Koepke, 2005). To the knowledge of the authors no study on the reconstruction of UV levels in a high alpine region above $3000 \mathrm{~m}$ has been performed. Lindfors and Vuilleumier (2005) reconstructed erythemal UV-doses for the alpine station Davos, which is located at an altitude of
$1580 \mathrm{~m}$ above sea level, but this is still $1526 \mathrm{~m}$ lower than the station Sonnblick used in this study. During the present study the first reconstruction for an alpine site, located at more than $3000 \mathrm{~m}$ above sea level, was performed. The unique location of the mountain observatory Hoher Sonnblick in Europe provides an opportunity to reconstruct solar UV for a high altitude alpine site and to investigate the influence of topography connected with high ground albedo and very low atmospheric pollution levels on UV trends.

The present study investigates first the influence of different temporal resolutions of input data on the reconstruction accuracy, it then performs a reconstruction for one high altitude alpine site and one low altitude site and investigates the contribution of the different meteorological parameters on the changes in UV. The investigation of changes in UV for the low altitude site of Vienna is especially of interest because this region is, with its 1.6 million inhabitants, the most populated one in Austria. These are to the knowledge of the authors new aspects in the domain of UV reconstruction.

\section{Data}

The Austrian national UV Monitoring network has been in operation since 1998 and has 12 stations all over the country. As already mentioned two stations out of this network have been selected to reconstruct past UV-doses. One station the observatory Hoher Sonnblick $\left(47^{\circ} 03^{\prime} \mathrm{N}, 12^{\circ} 57^{\prime} \mathrm{E}\right)$ is located in the central alps at an altitude of $3106 \mathrm{~m}$. The other one, Vienna $\left(48^{\circ} 15^{\prime} \mathrm{N}, 16^{\circ} 26^{\prime} \mathrm{E}\right)$, is located in the north-eastern part of the country at an altitude of $153 \mathrm{~m}$. These two stations were selected because of their significant differences in altitude, terrain and meteorological conditions. The data used in this study include UV erythemally weighted broadband irradiance, global irradiance (direct and diffuse global radiation), sunshine duration, snow height and snow cover as well as total ozone column.

\section{$2.1 \quad$ UV data}

In 1996, the setup of an Austrian UVB monitoring network was initiated by the Federal Department of Environment (Blumthaler and Schauberger, 2001). Now it consists of 12 broadband detectors for measuring erythemally weighted solar UV irradiance at locations between $153 \mathrm{~m}$ and $3106 \mathrm{~m}$ above sea level. All detectors are calibrated each year in the laboratory of the Division for Biomedical Physics, Innsbruck Medical University. First the relative spectral response of each detector is determined. Then by comparison with a double monochromator spectroradiometer the absolute calibration function is derived in dependence on solar zenith angle and on total atmospheric ozone (Blumthaler, 2004). The uncertainty of the calibration is about $\pm 7 \%$ (at $95 \%$ confidence level) for solar zenith angles $<75^{\circ}$, which is dominated by the uncertainty of the calibration lamp for 
the spectroradiometer $( \pm 4 \%)$. During routine operation, the measurements of all detectors are transmitted in near real time to the laboratory and then converted to UV-Indices, the internationally agreed unit for erythemally weighted solar irradiance. The results are then published on the internet (www.uv-index.at) every $15 \mathrm{~min}$, together with a regional map showing the distribution of the UV-Index over Austria by combining the information from the measurement detectors with cloud information from Meteosat Second Generation.

\section{Input data}

\subsection{Total ozone}

The total ozone content, usually given in Dobson Units (DU), is one of the most important parameters affecting UV-B radiation at the ground. Ground based measurements by Dobson (e.g. Dobson, 1931; Komyhr, 1980) and Brewer (e.g. Brewer, 1973; Kerr and McElroy, 1995) instruments are the most accurate and widely used method for the determination of atmospheric total ozone content. Because of the lack in local ozone data before 1994 at Hoher Sonnblick and the absence of ozone measurements in Vienna additional datasets from satellite, ground measurements as well as ozone model simulations were used. The total ozone record from Arosa is the world's longest, dating back to 1926 . This record has been homogenized and is discussed in detail by Staehelin et al. (1998a, b). In addition the simulated total ozone values over Europe were calculated within the scope of European Union's Action COST-726 project (Krzyścin, 2008). The ozone reconstruction model was trained on satellite data (NIWA assimilated total column ozone data base) over the period 1979-2004. The ozone values were reconstructed backward in time using the regression constants derived as a result of the training, time series of various atmospheric indices of the atmospheric circulation, and the meteorological variables. The quality of the data base is assured by a comparison of the modeled total ozone with the ground-based data taken at several Dobson stations which have been in operation since the early 1950s and 1960s. This set of data was also used in our study.

A comparison against the measured daily total ozone over Arosa provides that the mean difference, [(Model - Observation)/Observation]* $100 \%$, is $1.5 \% \pm 4.5 \%$ for the period 1976-2004. A high correspondence between the modeled and measured total ozone values over Arosa is also corroborated by Fig. 1a. The model estimates total ozone values at sea level pressure, thus an equivalent of measured total ozone at Arosa (site altitude $\sim 1850 \mathrm{~m}$ ) should be lowered by $\sim 1.5 \%$ because of the altitude effects, i.e. $\sim 1 \% / \mathrm{km}$ decrease of total ozone is approximated from an assumption that $\sim 10 \%$ of column ozone content is in the troposphere.

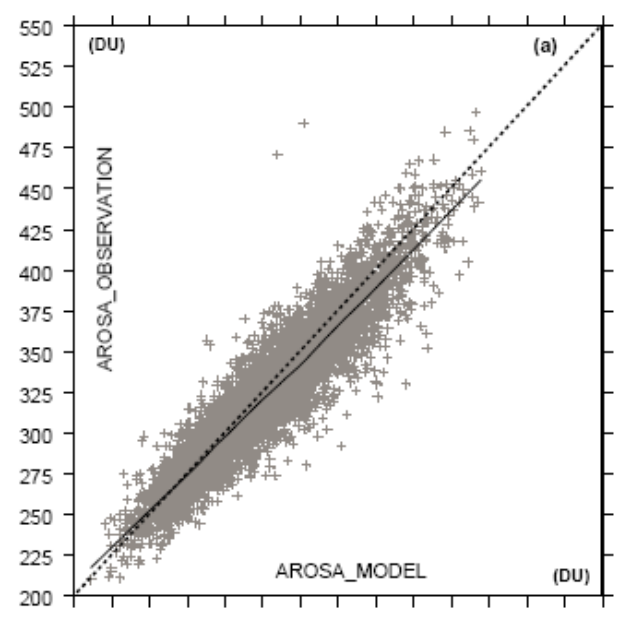

200225250275300325350375400425450475500525550
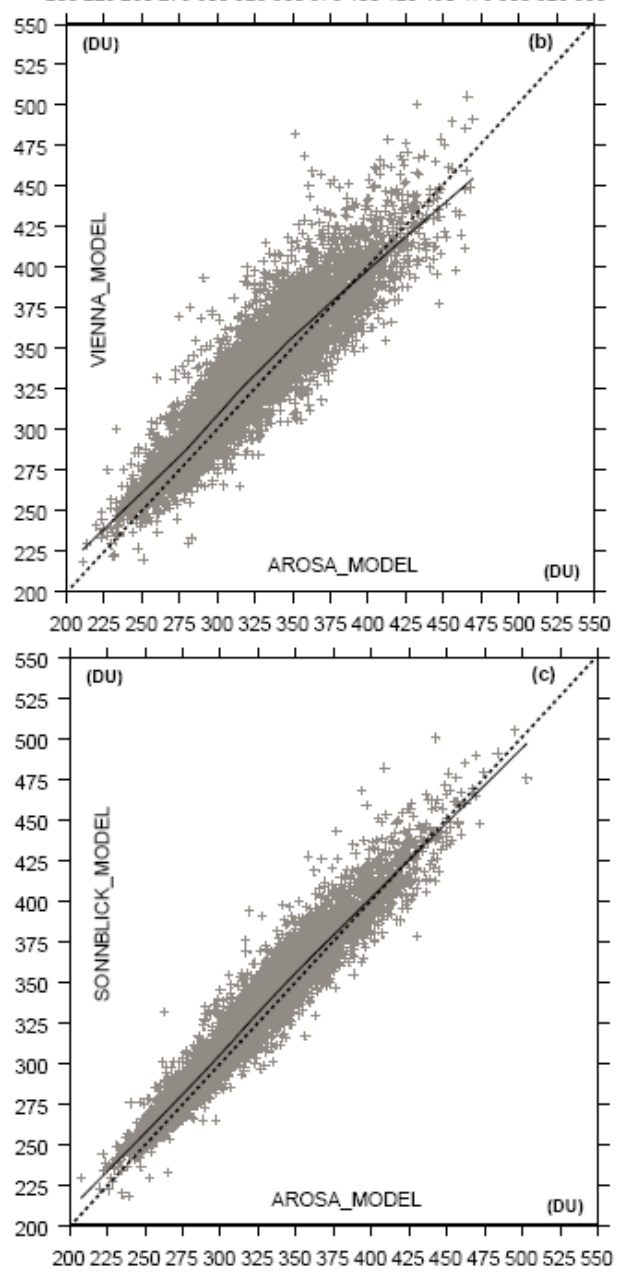

Fig. 1. Modeled versus observed daily mean total ozone values for Arosa (a), modeled daily ozone values for Vienna versus corresponding values for Arosa (b), modeled daily ozone values for Hoher Sonnblick versus corresponding values for Arosa (c). The results are presented for the 1976-2004 period. Solid curve represents smoothed pattern of the differences calculated by LOWES low pass filter. Dashed straight line shows a diagonal of the square. 
Table 1. Overview of the datasets used in this study.

\begin{tabular}{llll}
\hline Station & Coordinates & Data & Period \\
\hline Sonnblick & $47.03^{\circ} \mathrm{N}, 12^{\circ} 57^{\prime} \mathrm{E}$ & global irradiance & $1972-2005^{*}$ \\
& $3106 \mathrm{~m}$ a.s.l. & sunshine duration & $1972-2005$ \\
& & UV irradiance & $1998-2005$ \\
& & total ozone & $1994-2005$ \\
snow depth & $1972-2005$ \\
Vienna & $48^{\circ} 15^{\prime} \mathrm{N}, 16^{\circ} 26^{\prime} \mathrm{E}$ & global irradiance & $1960-2005$ \\
& $153 \mathrm{~m}$ a.s.1. & sunshine duration & $1960-2005$ \\
& & UV irradiance & $1998-2005$ \\
Arosa & $46.8^{\circ} \mathrm{N}, 9.7^{\circ} \mathrm{E}$ & snow depth & $1960-2005$ \\
& $1850 \mathrm{~m}$ a.s.l. & total ozone & $1960-2005$ \\
\hline
\end{tabular}

* The global irradiance record at Hoher Sonnblick had some gaps in the years 1973, 1981, 1983, 1984, 1988 and 1990.

We compared the modeled daily total ozone values for Arosa and Vienna (or Hoher Sonnblick), to investigate the relationship between the ozone values of these sites. The mean difference, [(Model_Vienna - Observation_Arosa)/Observation_Arosa] ${ }^{*} 100 \%$, is $4.0 \% \pm 6.5 \%$ and the correlation coefficient between the modeled values for Vienna and the observed ozone at Arosa is 0.92 (see also Fig. 1b). Thus, the total ozone values used for UV reconstruction over Vienna are just measured Arosa ozone enlarged by $4 \%$ (i.e., $2.5 \%$ comes from the latitude/longitude sites' differences and $1.5 \%$ is due to the altitude effect). Similar calculations done for Hoher Sonnblick showed that the measured total ozone for Arosa corresponds to total ozone that would be expected over Hoher Sonnblick at an altitude of $3100 \mathrm{~m}$ (see also Fig. 1c, which shows a comparison of modeled total ozone values for these sites). Moreover, the comparison of the measured monthly averages between the Austrian ozone data set and those from Arosa for the time period 1993 to 2006 shows that the differences are not higher than $\pm 3 \%$. We may therefore use the measured total ozone at Arosa to cover the whole period for Austria. The ozone record of Arosa has some periods of missing data (see Staehelin et al., 1998a, b) and for these periods missing values are filled up by the modeled COST-726 total ozone.

\subsection{Cloudiness, global irradiance and sunshine duration}

The use of cloud modification factors (CMFs), gained from information on global irradiance and sunshine duration, is a common method used by the scientific community to describe cloud effects on solar UV radiation (e.g. Kaurola et al., 2000; Schwander et al., 2002; Koepke et al., 2006).

European Union's Action COST 726 identified global irradiance in combination with cloud modification factors (CMFs) as the best way to describe cloud attenuation and cloud effects on solar UV (Koepke et al., 2006). Based on these findings, we used global irradiance data for our recon- struction study. During some periods (see Table 1) no records on global irradiance were available, for these periods we used data on sunshine duration to reconstruct global irradiance (see Sect. 4.3). Global irradiance and sunshine duration have been measured at both stations by the Austrian Central Institute for Meteorology and Geodynamics (ZAMG). The time series for global irradiance and sunshine duration at Hoher Sonnblick is dating back to the year 1972 while in Vienna information is available since the year 1960. The global irradiance time series has however some gaps at station Hoher Sonnblick (see Table 1). Sunshine duration was therefore used to fill the gaps. Sunshine duration was used to distinguish between clear-sky and cloudy conditions and to reconstruct global irradiance levels for some periods of the used time series. More information will be given in Sect. 4.3. To have comparable time periods at both stations the period 1976-2005 was chosen for further analysis. A detailed overview of datasets used in this study is shown in Table 1.

\subsection{Ground albedo, snow depth and snow amount}

Snow depth and snow amount are the most important factors influencing surface albedo in the UV range of the spectra and the relationship has been well studied (Blumthaler and Ambach, 1988; McKenzie et al., 1998; Weihs et al., 1999; Kylling et al., 2000; Weihs et al., 2001; Schmucki et al., 2002). The data on snow depth (accumulated quantity of snow) and snow amount (quantity of fresh snow) used in our study were measured by the Austrian Central Institute for Meteorology and Geodynamics (ZAMG). At Hoher Sonnblick measurements on snow depth and snow amount are available since 1972 while in Vienna information is available since 1960. Snow cover is the most important parameter for the calculations of the surface albedo (see Sect. 4.1).

\section{Methods}

In the following sections the reconstruction technique and calculation of input parameters for the reconstruction models is explained in detail.

\subsection{Calculating surface albedo values}

Because of the altitude the influence of snow cover on ground albedo is more important at the alpine station Hoher Sonnblick than in Vienna. Surface albedo values were calculated using a multiple regression model (Simic et al., 2005). The calculation for spring (March, April, May) and winter (December, January, February) is shown in Eq. (1) while the calculation for summer (June, July, August) and autumn (September, October, November) is given in Eq. (2).

$$
\begin{aligned}
& \text { Albedo }=0.156+2.27 \times 10^{-4} \times \text { SNOW } \\
& \quad+4.01 \times 10^{-3} \times \text { NSNOW }-1.954 \times 10^{-2} \times \text { DAYS }
\end{aligned}
$$




$$
\begin{aligned}
& \text { Albedo }=0.138+6.99 \times 10^{-4} \times \mathrm{SNOW} \\
& \quad+6.06 \times 10^{-3} \times \mathrm{NSNOW}-1.489 \times 10^{-2} \times \mathrm{DAYS}
\end{aligned}
$$

At Hoher Sonnblick snow height (SNOW), amount of fresh snow (NSNOW) and days since last snow fall (DAYS) are used as input for the multiple regression model. Snow Height (SNOW) and amount of fresh snow (NSNOW) are given in $\mathrm{cm}$. In Vienna snow cover is less frequent and we used fixed ground albedo values for snow covered and snow free ground conditions. If a snow height of more than $5 \mathrm{~mm}$ was reported in Vienna we used a value of 0.4 , if the snow cover was below this value we used a value of 0.03 to describe the surface albedo.

\subsection{Modelling clear-sky UV-values}

To model clear-sky UV-doses the model SDISORT developed by Stamnes et al. (1988) was used. This model needs information on date, time, location, altitude, solar zenith angle, total ozone column, surface albedo and aerosol characteristics as input parameters. An average aerosol optical depth at $400 \mathrm{~nm}$ of 0.06 at Sonnblick and of 0.35 in Vienna was used throughout all the simulations. An Ångstroem alpha coefficient (Ångstroem, 1929) of 1.2 was used to describe wavelength dependence.

The vertical aerosol profile is defined using three layers: $0-2 \mathrm{~km}, 2-10 \mathrm{~km}$ and $10-100 \mathrm{~km}$ altitude. The aerosol optical depth was set to 0.04 between 2 and $10 \mathrm{~km}$ and to 0.02 between 10 and $100 \mathrm{~km}$. The single scattering albedo was set to 0.9 in the troposphere and to 1 in the stratosphere. The ozone profile and the air temperature are defined for 30 atmospheric layers. Here the vertical profile of the US Standard Atmosphere 1976 was used. The dependence of the ozone cross section on temperature is taken into account during the calculations. The Rayleigh scattering is calculated using the formula by Nicolet (Nicolet, 1984) for each pressure slab. Phase function (asymmetry parameter) is required as well. Considering that we use some semi-empirical factors in our reconstruction method (see Eq. 8-11) the influence of the phase function may be considered as negligible.

\subsection{Reconstruction of global irradiance}

Global irradiance is needed to calculate the cloud modification factors for global irradiance. However, at station Hoher Sonnblick the global irradiance dataset has some gaps in the years 1973, 1981, 1983, 1984, 1988 and 1990. In order to fill these gaps we adapted an empirical approach developed by Neuwirth (1979) for the reconstruction of hourly mean values of global irradiance (Eq. 3).

$\mathrm{G}_{\mathrm{MOD}}=G_{\mathrm{REF}} \times f(n)$

Where $\mathrm{G}_{\mathrm{MOD}}$ is the modelled global irradiance and $f(n)$ is a correction factor being a climatological ratio between observed global irradiance $\left(\mathrm{G}_{\mathrm{OBS}}\right)$ and reference clear-sky global irradiance $\left(\mathrm{G}_{\mathrm{REF}}\right)$ under observed sunshine duration $(n)$ given in decimal hours. Using this modelling approach $90 \%$ of the modelled global irradiance values agree within $\pm 20 \%$ of the observed ones.

4.4 Calculation of cloud modification and correction factors

$\mathrm{CMF}_{\mathrm{G}(\mathrm{SZA})}=\frac{\mathrm{G}_{\mathrm{OBS}(\mathrm{SZA})}}{\mathrm{G}_{\mathrm{REF}(\mathrm{SZA})}}$

The cloud modification factor for global irradiance $\left(\mathrm{CMF}_{\mathrm{G}}\right)$ is calculated as shown in Eq. (4) as the ratio between observed $\left(G_{O B S}\right)$ and reference global irradiance $\left(G_{R E F}\right)$ for each solar zenith angle (SZA).

$\mathrm{CMF}_{\mathrm{UV}(\mathrm{SZA})}=\frac{\mathrm{UV}_{\mathrm{OBS}(\mathrm{SZA})}}{\mathrm{UV}_{\mathrm{MOD}(\mathrm{SZA})}}$

Corresponding to the cloud modification factor for global irradiance a cloud modification factor for the UV part of the spectra $\left(\mathrm{CMF}_{\mathrm{UV}}\right)$ is calculated as ratio between observed UV-dose (UV $\mathrm{UBS}_{\mathrm{OBS}}$ ) and modelled clear-sky UV-dose $\left(\mathrm{UV}_{\mathrm{MOD}}\right.$ ) for each solar zenith angle (SZA) (see Eq. 5). The CMF values were stored in look up tables for a solar zenith angle range between $19^{\circ}$ and $90^{\circ}$ using 2 degree interval resolution.

Correction factors are widely used within the scientific community to transfer the $\mathrm{CMF}_{\mathrm{G}}$ to a cloud modification factor in the UV range of the spectra $\left(\mathrm{CMF}_{\mathrm{UV}}\right)$ (e.g. Kaurola et al., 2000; Reuder and Koepke, 2005). The correction factor $(C)$ is calculated from a period of concurrent measurements of UV- and global radiation and modeled clear-sky values.

$C_{(x)}=\frac{\operatorname{CMF}_{U V}(x)}{\operatorname{CMF}_{G}(x)}$

The correction factor $\left(C_{(x)}\right)$ was calculated as mean ratio between $\mathrm{CMF}_{\mathrm{UV}}$ and $\mathrm{CMF}_{\mathrm{G}}$ over all solar zenith angles (see Eq. 6). Where $(x)$ means hourly or daily resolution of input data.

4.5 Reconstruction of erythemal UV-doses and analysis of the influence of different temporal resolutions on the model performance

As already mentioned in Sect. 3.2., we used global irradiance instead of sunshine duration to calculate past UV-doses. For the reconstruction an approach similar to the one described by Kaurola et al. (2000) has been used.

Kaurola et al. (2000) used modelled clear-sky UV values, a cloud modification factor for global irradiance and a correction factor in their study (Eq. 7).

$\mathrm{UV}_{\mathrm{REKO}}=\mathrm{UV}_{\mathrm{MOD}} \times \mathrm{CMF}_{\mathrm{G}} \times C$

Here $U V_{\text {REKO }}$ is the reconstructed UV-dose, UV $\mathrm{UVD}_{\text {MOD }}$ is the modelled UV-dose under clear-sky conditions, $\mathrm{CMF}_{\mathrm{G}}$ is the 
Table 2. Statistical numbers of the 4 modelling approaches for the stations Vienna (VIE) and Hoher Sonnblick (SON), showing correlation $R^{2}$, bias (in \%) and root mean square error (RMSE) (in \%) between model results and data. HMC = model with hourly resolution and monthly correction factor $C$, HSC $=$ model with hourly resolution and seasonal correction factor $C$, DMC $=$ model with daily resolution and monthly correction factor $C, \mathrm{DSC}=$ model with daily resolution and seasonal correction factor $C$.

\begin{tabular}{lcccccccccccc}
\hline Station/Model & \multicolumn{3}{c}{$R^{2}$} & \multicolumn{4}{c}{ BIAS } \\
\hline & winter & spring & summer & autumn & winter & spring & summer & autumn & winter & spring & summer & autumn \\
\hline VIE-HMC & 0.96 & 0.96 & 0.96 & 0.99 & +4 & +3 & +7 & -1 & 26 & 16 & 13 & 18 \\
VIE-HSC & 0.96 & 0.96 & 0.95 & 0.99 & +5 & +7 & +7 & +1 & 28 & 18 & 14 & 19 \\
VIE-DMC & 0.94 & 0.90 & 0.94 & 0.99 & -5 & -2 & +7 & +1 & 28 & 27 & 14 & 19 \\
VIE-DSC & 0.94 & 0.90 & 0.95 & 0.99 & -8 & -2 & +7 & +7 & 27 & 27 & 14 & 22 \\
SON-HMC & 0.96 & 0.96 & 0.97 & 0.98 & -2 & -2 & +1 & -8 & 18 & 15 & 11 & 18 \\
SON-HSC & 0.96 & 0.96 & 0.97 & 0.98 & -2 & -3 & +1 & -7 & 21 & 16 & 12 & 19 \\
SON-DMC & 0.91 & 0.93 & 0.94 & 0.98 & -2 & -7 & -3 & -13 & 25 & 22 & 18 & 24 \\
SON-DSC & 0.91 & 0.94 & 0.94 & 0.98 & +2 & -12 & -3 & -13 & 26 & 23 & 19 & 24 \\
\hline
\end{tabular}

cloud modification factor for global irradiance and $C$ is a yearly correction factor. For our purpose we have modified this approach for different temporal resolutions which are discussed in detail in the next paragraph.

To analyse the influence of temporal resolutions of input data, cloud modification and correction factors, 4 modelling approaches with different temporal resolution were developed (Eq. 8 to Eq. 11).

$$
\begin{aligned}
& \mathrm{UV}_{\mathrm{HMC}}=\mathrm{UV}_{\mathrm{MOD}(\mathrm{H})} \times \mathrm{CMF}_{\mathrm{G}(\mathrm{H})} \times C_{\mathrm{HM}} \\
& \mathrm{UV}_{\mathrm{HSC}}=\mathrm{UV}_{\mathrm{MOD}(\mathrm{H})} \times \mathrm{CMF}_{\mathrm{G}(\mathrm{H})} \times C_{\mathrm{HS}} \\
& \mathrm{UV}_{\mathrm{DMC}}=\mathrm{UV}_{\mathrm{MOD}(\mathrm{D})} \times \mathrm{CMF}_{\mathrm{G}(\mathrm{D})} \times C_{\mathrm{DM}} \\
& \mathrm{UV}_{\mathrm{DSC}}=\mathrm{UV}_{\mathrm{MOD}(\mathrm{D})} \times \mathrm{CMF}_{\mathrm{G}(\mathrm{D})} \times C_{\mathrm{DS}}
\end{aligned}
$$

As already mentioned above, we analyze the influence of different temporal resolution of input data on the reconstruction accuracy. Therefore - in contrast to other studies that used a single correction factor (e.g. Kaurola et al., 2000) - we computed monthly $\left(C_{\mathrm{HM}}, C_{\mathrm{DM}}\right)$ and seasonal $\left(C_{\mathrm{HS}}, C_{\mathrm{DS}}\right)$ correction factors to analyze whether a time varying correction factor improves the reconstruction accuracy. Where based on Eq. (6), $x$ means hourly (H) or daily resolution (D) of input data. Further we use $\mathrm{CH}$ and $\mathrm{CD}$ values averaged over each calendar month $\mathrm{M}\left(C_{\mathrm{HM}}\right.$ and $C_{\mathrm{DM}}$, respectively) or 3-month season $\mathrm{S}\left(C_{\mathrm{HS}}\right.$ and $C_{\mathrm{DS}}$, respectively). $\mathrm{UV}_{\mathrm{MOD}(\mathrm{H})}$ is modelled clear-sky UV-dose on hourly resolution, $\mathrm{UV}_{\mathrm{MOD}(\mathrm{D})}$ is modelled clear-sky UV-dose on daily resolution, $\mathrm{CMF}_{\mathrm{G}(\mathrm{H})}$ is a cloud modification factor for global irradiance on hourly resolution and $\mathrm{CMF}_{\mathrm{G}(\mathrm{D})}$ an average daily cloud modification factor for global irradiance.

For each station we defined two independent data sets: a 2 year development period and a 2 year testing period. For developing the model, data from the years 1999 and 2002 (Sonnblick) and 2000 and 2005 (Vienna) were used.
For testing the model, data from the years 2000 and 2003 (Sonnblick) and 2003 and 2004 (Vienna) were used. The combination of these years was chosen to ensure that an equivalent number of days for comparison is available. The performance of our 4 models is quite different throughout the year. Table 2 shows the correlation, root mean square error and bias between estimated and observed daily UVdoses for the different seasons of the year for all 4 modelling approaches. At station Hoher Sonnblick the HMC-Model shows the best fit between estimated and observed UV-doses for all 4 seasons. In Vienna the HMC-Model shows the best fit during the winter, spring and summer seasons while in autumn the reconstruction quality of the HMC, HSC and DMC are similar.

A more quantitative way to look at the performance of our reconstruction approaches for both stations can be seen in Table 3 (for Vienna) and Table 4 (for Hoher Sonnblick), where the relative distribution of the difference between the model and the data is shown. It is obvious that the reconstruction quality significantly increases with increasing temporal resolution of the input data. Altogether, most of the day-today variation is captured fairly well by our models and the results are comparable to those from other studies (e.g. Kaurola et al., 2000; Lindfors and Vuilleumier, 2005; Reuder and Koepke, 2005). This statement is valid for daily and monthly UV-doses, whereby the model using input data with highest temporal resolution (HMC) leads to the best agreement between observed and reconstructed UV-doses. The results in Tables 3 and 4 also point out that the performance of our reconstruction method is slightly better at Hoher Sonnblick than for Vienna. Possible reasons for that will be discussed later in this paper. 
Table 3. Distribution of the estimated UV-doses in comparison to the observed ones for the testing period in Vienna (in \%). HMC $=$ model with hourly resolution and monthly correction factor $C$, HSC $=$ model with hourly resolution and seasonal correction factor $C$, DMC $=$ model with daily resolution and monthly correction factor $C, \mathrm{DSC}=$ model with daily resolution and seasonal correction factor $C$.

\begin{tabular}{llcccccccc}
\hline Range & Station/Model & $\pm 5 \%$ & $\pm 10 \%$ & $\pm 15 \%$ & $\pm 20 \%$ & $\pm 25 \%$ & $\pm 30 \%$ & $\pm 35 \%$ & $\pm 40 \%$ \\
\hline Daily & VIE-HMC & $22 \%$ & $45 \%$ & $62 \%$ & $75 \%$ & $86 \%$ & $91 \%$ & $93 \%$ & $97 \%$ \\
data & VIE-HSC & $20 \%$ & $41 \%$ & $58 \%$ & $74 \%$ & $83 \%$ & $88 \%$ & $92 \%$ & $96 \%$ \\
& VIE-DMC & $17 \%$ & $39 \%$ & $53 \%$ & $69 \%$ & $75 \%$ & $80 \%$ & $85 \%$ & $89 \%$ \\
& VIE-DSC & $17 \%$ & $35 \%$ & $49 \%$ & $62 \%$ & $73 \%$ & $80 \%$ & $87 \%$ & $89 \%$ \\
\hline \multirow{2}{*}{ Monthly } & VIE-HMC & $50 \%$ & $67 \%$ & $96 \%$ & $96 \%$ & $100 \%$ & & & \\
data & VIE-HSC & $33 \%$ & $67 \%$ & $88 \%$ & $88 \%$ & $96 \%$ & $100 \%$ & & \\
& VIE-DMC & $42 \%$ & $67 \%$ & $88 \%$ & $92 \%$ & $100 \%$ & & & \\
& VIE-DSC & $42 \%$ & $46 \%$ & $75 \%$ & $92 \%$ & $100 \%$ & & & \\
\hline
\end{tabular}

Table 4. Same as Table 3. Results are shown for Hoher Sonnblick.

\begin{tabular}{llcccccccc}
\hline Range & Station/Model & $\pm 5 \%$ & $\pm 10 \%$ & $\pm 15 \%$ & $\pm 20 \%$ & $\pm 25 \%$ & $\pm 30 \%$ & $\pm 35 \%$ & $\pm 40 \%$ \\
\hline Daily & SON-HMC & $36 \%$ & $62 \%$ & $76 \%$ & $86 \%$ & $93 \%$ & $95 \%$ & $98 \%$ & $99 \%$ \\
data & SON-HSC & $31 \%$ & $53 \%$ & $71 \%$ & $82 \%$ & $90 \%$ & $95 \%$ & $97 \%$ & $98 \%$ \\
& SON-DMC & $19 \%$ & $39 \%$ & $49 \%$ & $60 \%$ & $69 \%$ & $76 \%$ & $81 \%$ & $84 \%$ \\
& SON-DSC & $20 \%$ & $37 \%$ & $50 \%$ & $58 \%$ & $69 \%$ & $75 \%$ & $78 \%$ & $84 \%$ \\
\hline \multirow{2}{*}{ Monthly } & SON-HMC & $67 \%$ & $96 \%$ & $100 \%$ & & & & & \\
& SON-HSC & $54 \%$ & $75 \%$ & $92 \%$ & $92 \%$ & $100 \%$ & & & \\
& SON-DMC & $42 \%$ & $58 \%$ & $71 \%$ & $96 \%$ & $96 \%$ & $100 \%$ & & \\
& SON-DSC & $25 \%$ & $42 \%$ & $79 \%$ & $88 \%$ & $92 \%$ & $100 \%$ & & \\
\hline
\end{tabular}

\subsection{Performance of the HMC-model}

As already mentioned, the results of the statistical analysis of the testing period (Tables 2-4) showed that the model with the highest temporal resolution (HMC) shows the best agreement between observed and modelled UV-doses. Following this it was used for the reconstruction of past UV-doses and further discussion of model performance and results is just addressed for this model type. Figures 2 (Vienna) and 3 (Hoher Sonnblick) show the correlation between observed and modelled UV-dose for the testing period using the HMCModel for the different seasons. The results show a good agreement throughout the year. The correlation coefficient for all seasons is between 0.96 and 0.98 at Hoher Sonnblick and 0.96 and 0.99 in Vienna. The Bias is between -8 and +1 percent at Hoher Sonnblick and between -1 and +7 percent in Vienna. The values of the root mean square error are between +18 and +11 percent at Hoher Sonnblick and between +26 and +13 percent in Vienna.

\section{Results}

Using the HMC-model, hourly and daily erythemal UVdoses at Hoher Sonnblick and Vienna were estimated for the last decades. The following comparison concentrates on the period 1976-2005 in order to have a comparable 30 year period of data at both stations.

\subsection{Total ozone column}

The total ozone series of Arosa, Switzerland shows a decreasing trend since the 1970 s followed by a slight increase from the mid 1990s on. In this study we focused on the period 1976-2005 as this is the period we analyzed for UVchanges and compared the ten year ozone averages of the periods (1986-1995, 1996-2005) to the ten year average of the reference period 1976-1985. Here we found for the total ozone column during the period 1986-1995 an average reduction of $5 \%$ in winter, $4 \%$ in spring and $2 \%$ in summer and autumn. For the period 1996-2005 an average reduction in the ozone content of $4 \%$ for the winter months, $6 \%$ for spring, $4 \%$ for summer and only $1 \%$ for autumn was found. For the yearly averages we found a reduction in total ozone of 4\% for the period 1986-1995 and of 5\% for the period 1996-2005 in comparison to the reference period (Table 5). 

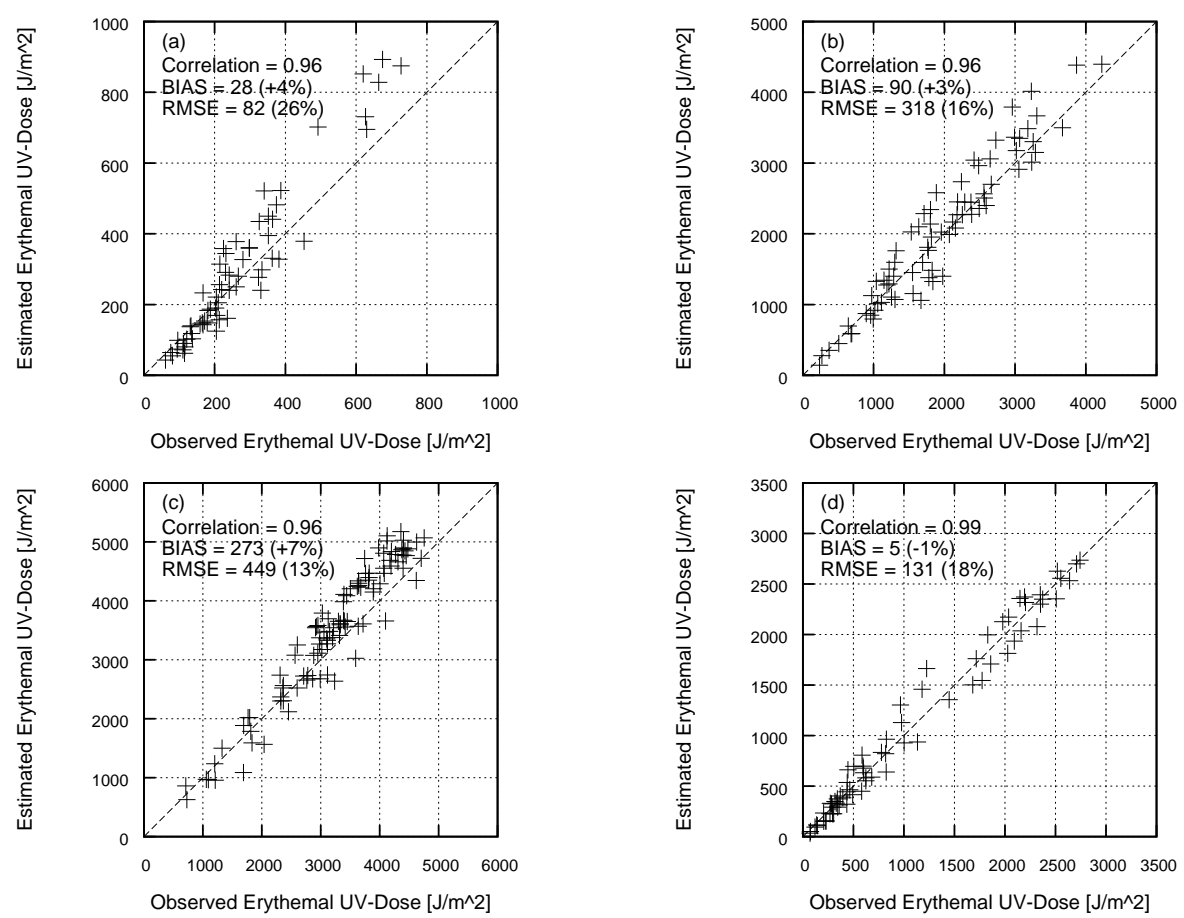

Fig. 2. Observed versus estimated daily erythemal UV-doses calculated with the HMC-Model for the testing period in Vienna. The Root Mean Square Error (RMSE) and the bias of the estimated UV-doses compared to the observed ones are also shown, as well as the correlation coefficient between estimated and observed UV- doses. (a) shows the comparison for Winter, (b) for Spring, (c) for Summer and (d) for Autumn. Winter is December-February, spring is March-May, summer is June-August and autumn is September-November.
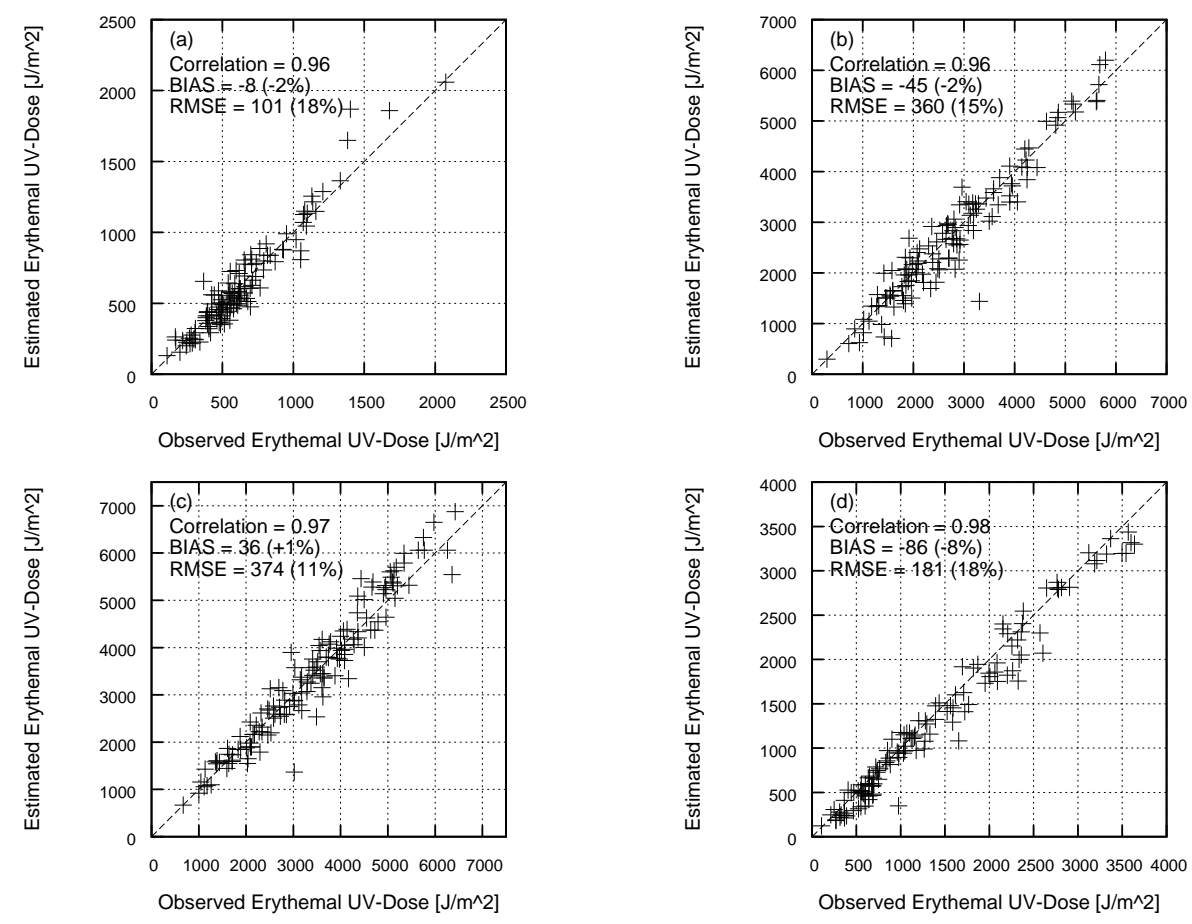

Fig. 3. Same as Fig. 2. Results are shown for Hoher Sonnblick. 
Table 5. Changes in mean values of the estimated erythemal UV-doses, total ozone (TOC) and relative sunshine duration (SD) for the periods 1986-1995 and 1996-2005 in comparison to the reference period 1976-1985. Standard errors of estimated erythemal UV-doses are given in brackets.

\begin{tabular}{llcccccc}
\hline \multirow{2}{*}{ Station } & \multirow{2}{*}{ Season } & \multicolumn{2}{c}{ UV } & \multicolumn{2}{c}{ TOC } & \multicolumn{2}{c}{ SD } \\
& & $1986-1995$ & $1996-2005$ & $1986-1995$ & $1996-2005$ & $1986-1995$ & $1996-2005$ \\
\hline \multirow{2}{*}{ Vienna } & Winter & $+29 \%(1.7 \%)$ & $+18 \%(4.7 \%)$ & $-5 \%$ & $-4 \%$ & $+20 \%$ & $+10 \%$ \\
& Spring & $+9 \%(1.1 \%)$ & $+20 \%(4.1 \%)$ & $-4 \%$ & $-6 \%$ & $+2 \%$ & $+13 \%$ \\
& Summer & $+12 \%(0.9 \%)$ & $+8 \%(3.9 \%)$ & $-2 \%$ & $-4 \%$ & $+11 \%$ & $+14 \%$ \\
& Autumn & $+10 \%(1.2 \%)$ & $+10 \%(4.2 \%)$ & $-2 \%$ & $-1 \%$ & $+2 \%$ & $\pm 0 \%$ \\
\hline \multirow{2}{*}{ Sonnblick } & Winter & $+14 \%(2.7 \%)$ & $+22 \%(2.2 \%)$ & $-5 \%$ & $-4 \%$ & $+18 \%$ & $+17 \%$ \\
& Spring & $+7 \%(2.5 \%)$ & $+19 \%(2.0 \%)$ & $-4 \%$ & $-6 \%$ & $-2 \%$ & $+10 \%$ \\
& Summer & $\pm 0 \%(2.3 \%)$ & $\pm 0 \%(1.7 \%)$ & $-2 \%$ & $-4 \%$ & $+5 \%$ & $+8 \%$ \\
& Autumn & $-1 \%(2.7 \%)$ & $+10 \%(2.2 \%)$ & $-2 \%$ & $-1 \%$ & $-6 \%$ & $-3 \%$ \\
\hline
\end{tabular}

\subsection{Relative sunshine duration}

For the period 1986-1995 in Vienna we found an increase in relative sunshine duration of $20 \%$ in winter, $2 \%$ in spring, $11 \%$ in summer and $2 \%$ in autumn in comparison to the reference period 1976-1985. For the second period 1996-2005 we found in comparison to the reference period 1976-1985 an increase of $10 \%$ in winter, $13 \%$ in spring, $14 \%$ in summer and no change in autumn. At Hoher Sonnblick we found an increase in relative sunshine duration of $18 \%$ in winter and $5 \%$ in summer for the period 1986-1995 in comparison to 1976-1985. For the same period we found a decrease in relative sunshine duration of about $2 \%$ in spring and $6 \%$ in autumn. For the period 1996-2005 we found an increase in relative sunshine duration of $17 \%$ in winter, $10 \%$ in spring and $8 \%$ in summer in comparison to the reference period. In the same time interval the dataset for autumn shows a decrease of $3 \%$ in comparison to the reference period. The results for seasonal changes in relative sunshine duration are summarized in Table 5. For the yearly averages of relative sunshine duration we found an increase during the period 1986-1995 of $4 \%$ in Vienna and $3 \%$ at Hoher Sonnblick while an increase of $7 \%$ at both stations was found for the period 19962005 in comparison to the reference period 1976-1985.

\subsection{Erythemal UV-dose}

Figure 4 shows the yearly averages of estimated UV-doses compared with yearly averages of total ozone since 1976 for both stations. In comparison to the reference period 19761985 we found an increase in the yearly averages of erythemal UV-dose for the period 1986-1995 of 11\% $( \pm 1 \%)$ in Vienna and $2 \%( \pm 1.9 \%)$ at Hoher Sonnblick and for the period 1996-2005 of 17\% $( \pm 4 \%)$ in Vienna and 9\% $( \pm 2.4 \%)$ at Hoher Sonnblick.

The uncertainty is calculated as the standard error of the 10 -year seasonal mean value calculated from all pertaining daily values. Standard error of the mean is inferred as stan-

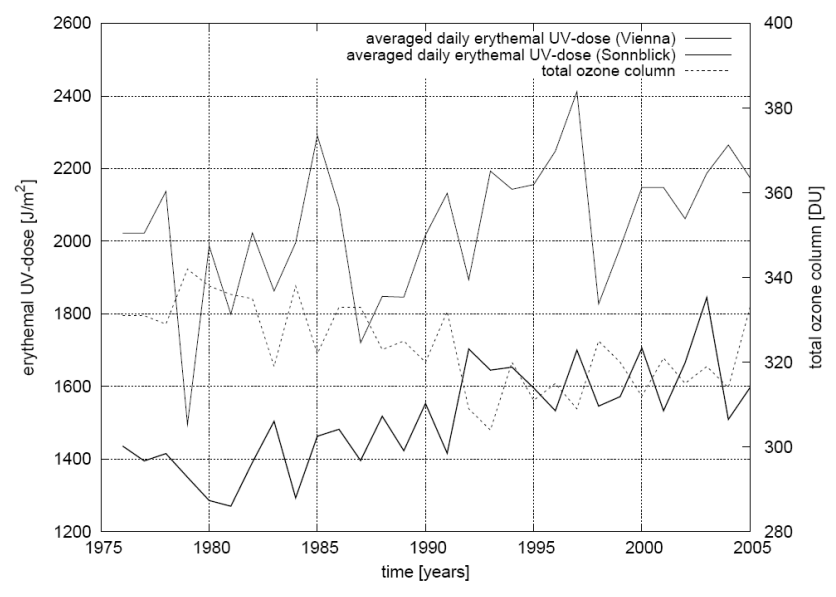

Fig. 4. Yearly averages of estimated UV-dose, compared to total ozone column at Hoher Sonnblick and Vienna from 1976-2005.

dard error of the daily UV estimate (shown in Table 2) divided by square root of the number of independent daily data (i.e., degree of freedom). To calculate the degree of freedom we arbitrarily assume that there is a 4-day span between independent daily UV data. This period roughly reflects persistence time of the weather pattern system over the sites. Figure 5 shows the yearly averages of estimated UV-doses and relative sunshine duration since 1976 for both stations.

On seasonal scale for the period 1986-1995 we found an increase in erythemal UV-dose in Vienna of $29 \%$ in winter, $9 \%$ in spring and autumn and $12 \%$ in summer in comparison to the period 1976-1985. During the period 1996-2005 the erythemal UV-dose increases in Vienna at about $18 \%$ in winter, $20 \%$ in spring, $8 \%$ in summer and $10 \%$ in autumn. For Vienna the seasonal uncertainty is within $\pm 1.7 \%$ for the period 1986-1995 and within $\pm 4.7 \%$ for the period $1996-2005$ (see Table 5). During the period 1986-1995 the erythemal UV-dose at Hoher Sonnblick increases about $14 \%$ in winter 


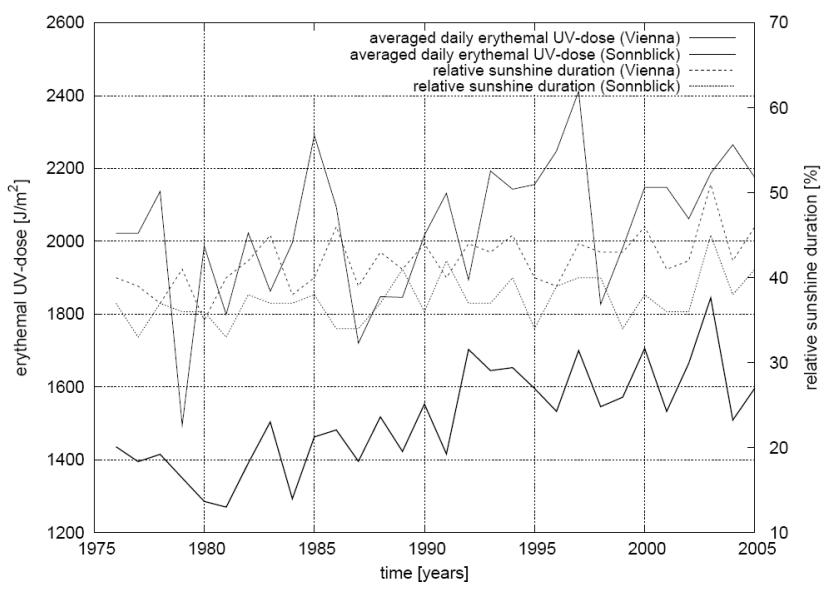

Fig. 5. Yearly averages of estimated UV-dose, compared to relative sunshine duration at Hoher Sonnblick and Vienna from 1976-2005.

and $7 \%$ in spring. Within the same time interval a small reduction of only $1 \%$ can be stated for autumn. Also during 1996 to 2005 there is a remarkable increase of the erythemal UV-dose of about $22 \%$ in wintertime, $19 \%$ in the spring months and $10 \%$ in autumn. Surprisingly there is no change during the summer within both periods when compared to the reference time. The seasonal uncertainty of these estimates is within $\pm 2.7 \%$ for the period 1986-1995 and within $\pm 2.2 \%$ for the period 1996-2005 (see Table 5). The results for seasonal changes in erythemal UV-dose at both stations are summarized in Table 5. The results of the calculated averages of erythemal UV-doses and atmospheric total ozone content are plotted in Fig. 6a-d for each season separately. The plots of the seasonal averages of erythemal UV-dose compared to the relative sunshine duration are shown in Fig. 7a-d.

5.4 Influence of ozone and sunshine duration on erythemal UV-dose

To identify the influence of total ozone content and sunshine duration on the erythemal UV-doses we performed model simulations holding total ozone and sunshine duration fixed at 1960s levels. Because of a lack in global irradiance data we could not reconstruct erythemal UV-doses back to 1960. Nevertheless, due to availability of data for total ozone and sunshine duration, control runs for 1960s conditions could be performed. We calculated the influence of changes in total ozone on erythemal UV-doses following Eq. (12) and the influence of changes in cloud cover following Eq. (13).

$\mathrm{M}_{\mathrm{TOC}}=\frac{\mathrm{UV}_{\mathrm{KSD}}}{\mathrm{UV}_{\mathrm{REKO}}} \times 100$

$\mathrm{M}_{\mathrm{SD}}=\frac{\mathrm{UV}_{\mathrm{KTOC}}}{\mathrm{UV}_{\mathrm{REKO}}} \times 100$

Where $\mathrm{M}_{\mathrm{TOC}}$ is the change in erythemal UV-dose through the influence of total ozone, $\mathrm{M}_{\mathrm{SD}}$ is the change in erythe-
Table 6. Influence of changes in total ozone (TOC) and of changes in relative sunshine duration (SD) on the seasonal averages of erythemal UV-dose during the periods 1986-1995 and 1996-2005 in comparison to 1976-1985.

\begin{tabular}{llcccc}
\hline \multirow{2}{*}{ Station } & \multirow{2}{*}{ Season } & \multicolumn{2}{c}{$1986-1995$} & \multicolumn{2}{c}{$1996-2005$} \\
& & TOC & SD & TOC & SD \\
\hline \multirow{2}{*}{ Vienna } & Winter & $60 \%$ & $40 \%$ & $70 \%$ & $30 \%$ \\
& Spring & $88 \%$ & $12 \%$ & $55 \%$ & $45 \%$ \\
& Summer & $66 \%$ & $34 \%$ & $60 \%$ & $40 \%$ \\
& Autumn & $64 \%$ & $36 \%$ & $65 \%$ & $35 \%$ \\
\hline \multirow{6}{*}{ Sonnblick } & Winter & $43 \%$ & $57 \%$ & $60 \%$ & $40 \%$ \\
& Spring & $100 \%$ & $0 \%$ & $53 \%$ & $47 \%$ \\
& Summer & $50 \%$ & $50 \%$ & $50 \%$ & $50 \%$ \\
& Autumn & $0 \%$ & $100 \%$ & $100 \%$ & $0 \%$ \\
\hline
\end{tabular}

Table 7. Influence of changes in total ozone (TOC) and of changes in relative sunshine duration (SD) on the yearly averages of erythemal UV-dose during the periods 1986-1995 and 1996-2005 in comparison to the reference period 1976-1985.

\begin{tabular}{lcrrr}
\hline \multirow{2}{*}{ Station } & \multicolumn{2}{c}{$1986-1995$} & \multicolumn{2}{c}{$1996-2005$} \\
& TOC & SD & TOC & SD \\
\hline Vienna & $66 \%$ & $34 \%$ & $50 \%$ & $50 \%$ \\
Sonnblick & $66 \%$ & $34 \%$ & $78 \%$ & $22 \%$ \\
\hline
\end{tabular}

mal UV-dose through the influence of changes in cloudiness, $\mathrm{UV}_{\text {REKO }}$ is the reconstructed UV-dose under observed conditions, $\mathrm{UV}_{\mathrm{KSD}}$ is reconstructed $\mathrm{UV}$-dose holding cloudiness constant on 1960s levels, $\mathrm{UV}_{\mathrm{KTOC}}$ is reconstructed UV-dose holding total ozone fixed on 1960s levels.

Using this technique we found out that changes in total ozone play in most cases the dominant role for changes in erythemal UV-dose at both stations (Tables 6 and 7). In Vienna during the period 1986-1995 for winter, summer and autumn more than $60 \%$ of the changes in erythemal UVdose result from changes in total ozone. During spring season about $88 \%$ of the changes in erythemal UV-dose result from the decrease in total ozone. For the period 1996-2005 we found similar results. Here about $60 \%$ of the changes in erythemal UV-doses arise from changes in total ozone during spring, summer and autumn. During winter we found that $70 \%$ of the changes in erythemal UV-doses result from changes in total ozone and only $30 \%$ arise because of the increase in relative sunshine duration. At Station Hoher Sonnblick during the period 1986-1995 an equal influence of changes in total ozone and sunshine duration during winter and summer was found. Half of this increase in erythemal UV-doses occurs through a decrease in total ozone, the other one through the increase in sunshine duration. During 

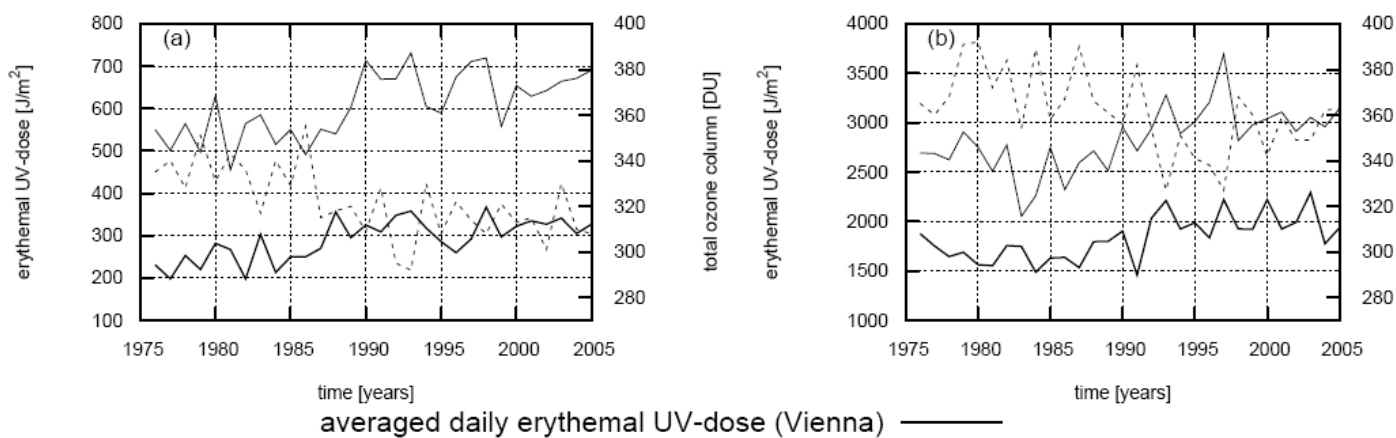

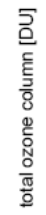
averaged daily erythemal UV-dose (Sonnblick)

total ozone column
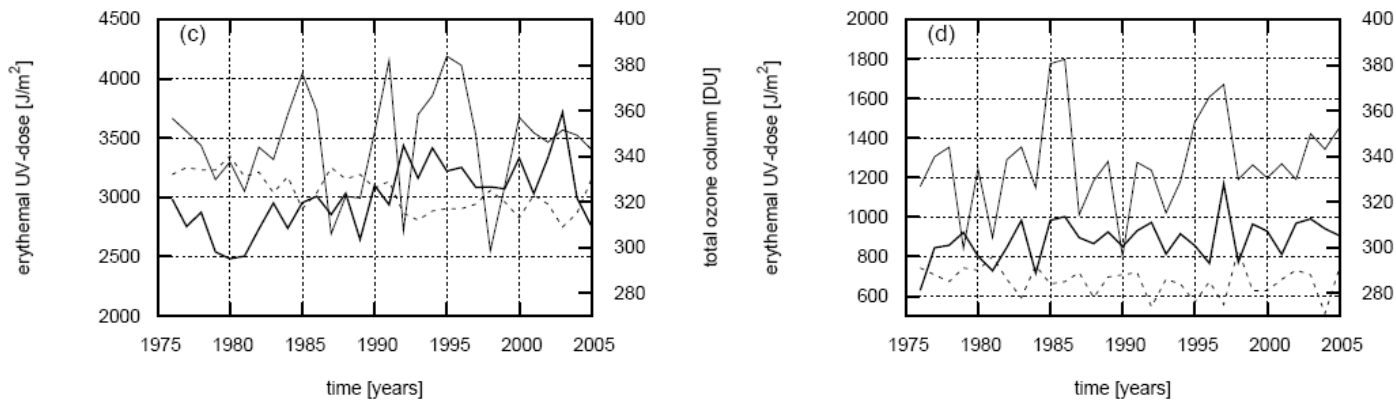

Fig. 6. Time series of estimated UV-dose and total ozone for the different seasons at the stations Hoher Sonnblick and Vienna from 19762005. Winter (a) is December-February, spring (b) is March-May, summer (c) is June-August and autumn (d) is September-November.
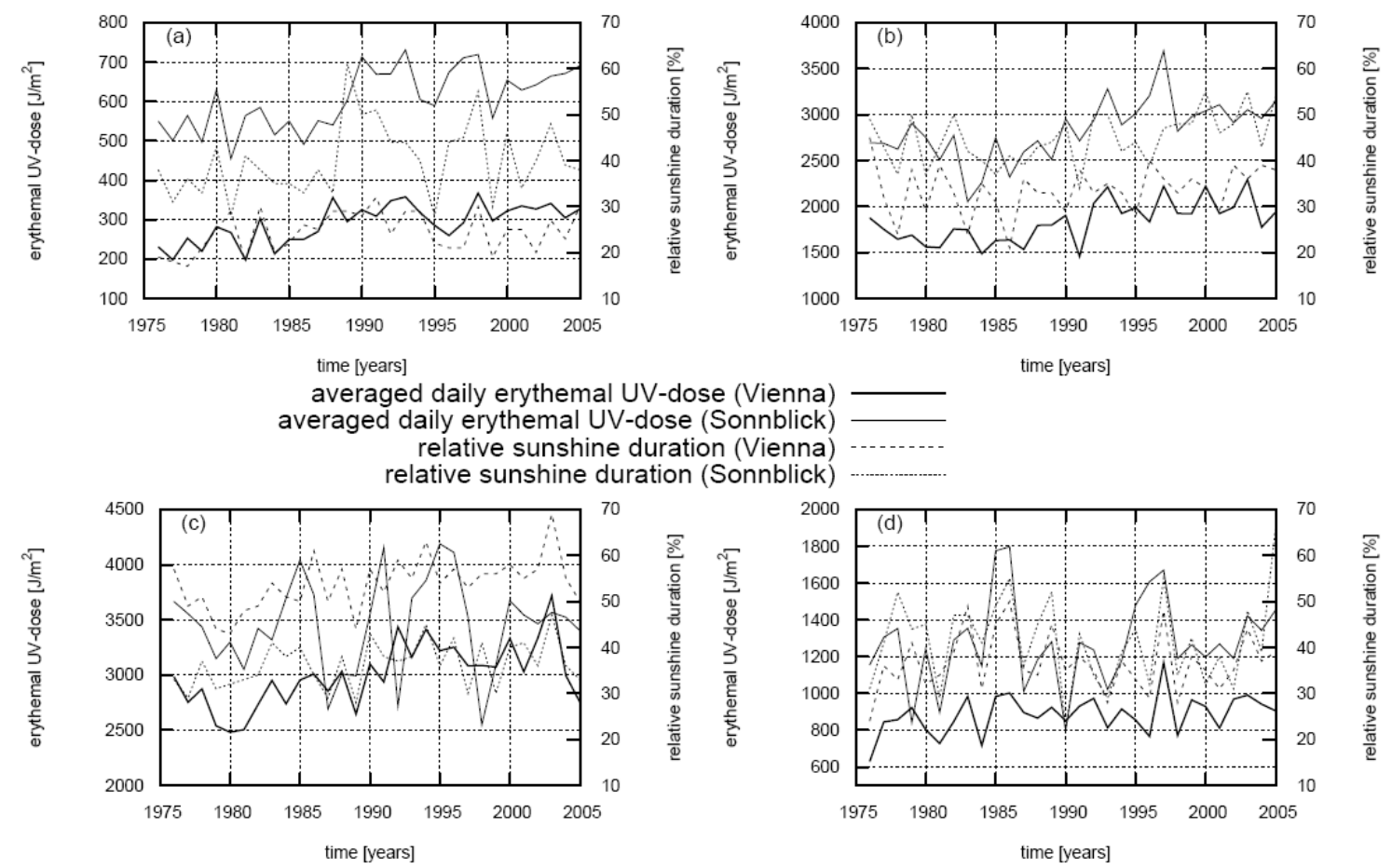

Fig. 7. Time series of estimated UV-dose and relative sunshine duration for the different seasons at stations Hoher Sonnblick and Vienna from 1972-2005. Winter (a) is December-February, spring (b) is March-May, summer (c) is June-August and autumn (d) is SeptemberNovember. 
springtime the decrease in total ozone is the major influencing factor on erythemal UV-dose. The small decrease in sunshine duration shows almost no effect on the erythemal UVdose. In autumn the small decrease in erythemal UV-dose results only from a decrease in relative sunshine duration. In the period 1996-2005 during winter, $60 \%$ of the changes in erythemal UV-dose result from decreasing total ozone. For spring and summer, change in the erythemal UV-dose is due to changes in cloudiness and changes in total ozone. For autumn the control run shows a decrease in erythemal UVdose resulting from the decrease in cloudiness. Because of that the decrease in total ozone is the main cause for the overall increase in erythemal UV-dose. The results for the different periods of the year are summarized for both stations in Table 6. For Vienna in the period 1986-1995 about $66 \%$ of the changes in the yearly averages of the erythemal UV-dose result from changes in total ozone, whereas 34\% are caused through changes in cloudiness. During the period 1996-2005 the changes in yearly averages of erythemal UV-dose at Vienna are partly caused by decreasing total ozone and partly by changes in cloudiness. This indicates that during the last years changes in cloudiness became more important for changes in erythemal UV-dose at Vienna than during the decades before. During the period 1986-1995 at Hoher Sonnblick 66\% of the changes in erythemal UV-dose result from changes in total ozone while about $34 \%$ result from changes in cloudiness. For the period 1996-2005 we found that the major influence on the average change in erythemal UV-dose was total ozone. Here $78 \%$ of the changes in erythemal UV-dose are caused by decreasing total ozone. These results are summarized in Table 7 .

\section{Summary and discussion}

In our study we performed the first reconstruction for erythemal UV-doses in Austria for one alpine and one urban region. A method developed by Kaurola et al. (2000) was adapted to our stations. The method, which is fairly simple uses modelled clear-sky UV-dose, cloud modification factors and correction factors and enables the estimation of UV-dose at Hoher Sonnblick and in Vienna for the last decades. For the modelling of clear-sky UV-doses we used SDISORT developed by Stamnes et al. (1988). Further we analysed the influence of temporal resolution of input data, cloud modification factors and correction factors on the model performance. The improvement in modelling accuracy by changing the time resolution could therefore be estimated. The results of the testing period show clearly that those modelling approach using input data and modification factors with the highest temporal resolution shows the best fit between estimated and observed UV-doses. The improvement of the accuracy achieved with hourly resolution varies with the seasons. In average the use of hourly resolution improves the accuracy of the reconstruction by $4 \%$ in Vienna and $8 \%$ at
Hoher Sonnblick. For the different seasons we gain an improvement in the reconstruction quality in Vienna of $1 \%$ in winter and summer, $3 \%$ in autumn and $11 \%$ in spring. At Hoher Sonnblick the use of hourly data with monthly correction factors improves the reconstruction quality by $6 \%$ in autumn and $8 \%$ in the other seasons in comparison to the use of daily datasets.

The estimated UV-doses using the HMC-Model were found to be in good agreement with measurements and the results are comparable to those from other studies. Especially the modelled monthly values are in good agreement with the observed ones. At Hoher Sonnblick all cases can be found within $\pm 15 \%$ of the observed ones while at Vienna $96 \%$ of the cases can be found within $\pm 15 \%$ of the observed values. It is important to note that the agreement between estimated and observed values is higher at station Hoher Sonnblick which might be first due to the higher aerosol loads in Vienna and second due to the determination of surface albedo using a regression model at Sonnblick while in Vienna fixed values depending on the presence or absence of snow cover were used to describe the surface albedo.

Because of a lack in direct measurements the aerosol optical depth (AOD) was assumed to be constant throughout the whole reconstruction period. At $400 \mathrm{~nm}$ AOD was set to 0.35 for Vienna and 0.06 for Hoher Sonnblick. To estimate the uncertainty arising from constant AOD values, the trends and fluctuations in AOD reported in literature were considered and additional model runs were performed. According to Weihs et al. (1999) daily and seasonal AOD values at Hoher Sonnblick ranged between 0.01 and 0.08 at $367 \mathrm{~nm}$. The observed fluctuations in AOD are higher than the absolute value of the trend per decade in AOD mentioned by Ruckstuhl et al. (2008) for Jungfraujoch. This trend is estimated at -0.02 at $550 \mathrm{~nm}$ over the period 1995 to 2005 , which roughly corresponds to a trend in AOD of -0.03 to -0.04 at $367 \mathrm{~nm}$ if an Angstrom alpha coefficient of 1.2 is assumed.

Based on these statements, we performed simulations of erythemal UV irradiance as a function of changes in AOD for Hoher Sonnblick. Our model simulations showed that maximum fluctuations in AOD of 0.07 at $367 \mathrm{~nm}$ may lead to changes in erythemal UV-dose of up to $2 \%$. However, the cloud modification factor (which is also used during clear sky conditions) and the correction factor $C$ are partly (within $1 \%$ ) able to represent these changes in UV-dose. An error smaller than $1 \%$ is therefore expected from uncertainties of AOD model input parameters at Hoher Sonnblick.

For larger aerosol optical depths fluctuations - such as in Vienna - CMF and correction factor $C$ are less able to account for changes in the erythemal UV range due to aerosols.

The short term (daily, weekly) fluctuations are however higher than the long year trends reported in the literature. All studies mention first an increase in aerosol optical depth which seems to have started between 1950 and 1960 (Makowski et al., 2008). The period where the maximum 
atmospheric turbidity was reached in Middle Europe was in the period from 1970 to 1990 where diurnal temperature ranges - which were identified as indicators for the transmittance of the atmosphere in the short wavelength range - were at a minimum (Makowski et al., 2008). Tegen et al. (2000) showed that between the years 1970 to 1990 the increase in AOD at $550 \mathrm{~nm}$ was not larger than 0.06 , which roughly corresponds to an increase in AOD of 0.1 at $400 \mathrm{~nm}$. After this period, a cleaning of the atmosphere was observed: optical depths measurements performed at $320 \mathrm{~nm}$ between 1990 and 2007 in Uccle (Belgium) and in Thessaloniki (Greece) (Cheymol and De Baker, 2003; Kazadzis et al., 2007) showed a decrease in AOD between 0.3 and 0.2 which corresponds to a maximum decrease in AOD of 0.2 at $400 \mathrm{~nm}$. Other measurements performed in Germany and Switzerland (Ruckstuhl et al., 2008) showed a decrease in AOD at all the stations, with a maximum decrease in AOD at $550 \mathrm{~nm}$ of 0.12 per decade at station Lindenberg. This roughly also corresponds to a decrease in AOD at $400 \mathrm{~nm}$ around 0.2. Trends in Southern Germany or in Switzerland were however half the amplitude of the changes recorded in Eastern Germany.

Under the assumption that an aerosol trend of 0.2 at $400 \mathrm{~nm}$ - comparable to Belgium, Southern Germany or Switzerland - may be assumed for Vienna between 1990 and 2007, we may therefore expect an uncertainty in erythemal UV-doses of 2-4\%. The trends shown in section 5 therefore probably underestimate the UV-doses during the period 1996 to 2005 by 2 to $4 \%$. At station Hoher Sonnblick for some years (see Table 1) global irradiance had to be reconstructed because of a lack in the observation record. The uncertainty for estimated erythemal UV-doses resulting from the estimated global irradiance reconstruction error is within $\pm 1 \%$ for the period $1976-1985$ and within $\pm 0.5 \%$ for the period 1986-1995. Another source of uncertainty was the lack of total ozone data in Vienna and at Hoher Sonnblick before the year 1994. Alternative ozone data from Arosa (CH), satellite data and ozone data obtained from modelling (see Sect. 3.1) had therefore to be used. We compared the monthly means of total ozone between Hoher Sonnblick and Arosa and found that the difference in the period 1994-1998 did not exceed \pm 3 percent. Through the results of a careful statistical analysis we finally believe that the alternative ozone dataset used in periods with missing total ozone observations over Arosa should not be a major source of uncertainty, because the alternative dataset of total ozone, i.e., COST-726 total ozone data base containing reconstructed (and reliable) daily total ozone values over Europe since 1950, were used to fill the data gaps. Moreover, the examination of COST-726 total ozone data supports the use of the Arosa total ozone as a valid proxy for the Austrian ozone (see Fig. 1). The analysis of our reconstructed time series shows a clear signal of increasing UV-dose in the last two decades in Austria. A higher increase in UV-dose was calculated for the winter and spring season, and this is explained by a larger decrease in total ozone in combination with an increase in sunshine duration. The results from our control run show that generally, changes in total ozone have influenced erythemal UVdose more than changes in cloudiness. However, these results have also shown that over Vienna in the recent years the influence of changes in cloudiness on UV-doses became significantly larger. This study provides important information for epidemiological studies and for future required medical care in Austria, knowing that erythemal UV-dose is one of the major causes for development of skin cancer.

Acknowledgements. The Authors want to thank the Austrian Central Institute for Meteorology and Geodynamics (ZAMG) for providing data on global irradiance, sunshine duration and snow and R. Stuebi from the Swiss Federal Office of Meteorology and Climatology (MeteoSwiss) for providing ozone datasets from Arosa. We are grateful to A. Vacek and H. Formayer from the Institute for Meteorology, University of Natural Resources and Applied Life Sciences, Vienna, for computational assistance with the datasets used in this study.

Further the authors want to thank two anonymous referees and Julian Groebner for useful comments that helped to improve the quality of the manuscript.

This work was performed within the scope of the European Union's action COST 726 "Long term changes and climatology of UV radiation over Europe" and SCOUT-O3: Stratosphere-Climate Links with Emphasis on the UTLS.

Edited by: J. Groebner

\section{References}

Ångstroem, A.: On the Atmospheric Transmission of Sun Radiation and on Dust in the Air, Geografiska Annaler, 11, 156-166, 1929.

Blumthaler, M. and Ambach, W.: Solar UVB-albedo of various surfaces, Photochem. Photobiol., 48, 85-88, 1988.

Blumthaler, M.: Quality assurance and quality control methodologies within the Austrian UV monitoring network, Rad. Prot. Dos., 111, 359-362, 2004.

Brewer, A. W.: A replacement for the Dobson spectrophotometer?, Pure Appl. Geophys., 106-108, 919-927, 1973.

Burrows, W. R.: CART regression models for predicting UV radiation at the ground in the presence of cloud and other environmental factors, J. Appl. Meteorol., 36, 531-544, 1997.

Calbó, J., Pagès, D., and González, J.-A.: Empirical studies of cloud effects on UV radiation: a review, Rev. Geophys., 43, 155-183, 2005.

Cheymol, A. and De Backer, H.: Retrieval of the aerosol optical depth in the UV-B at Uccle from Brewer ozone measurements over a long time period 1984-2002, J. Geophys. Res., 108(D24), 4800, doi:10.1029/2003JD003758, 2003.

Commission Internationale de l'Eclairage (CIE): 134/1, TC 6-26 Report: Standardization of the terms UV-A1, UV-A2 and UV-B, in Collection in Photobiology and Photochemistry, Comm. Int. de l'Eclairage, Vienna, 1999.

Den Outer, P. N., Slaper, H., and Tax, R. B.: UV radiation in the Netherlands: Assessing long-term variability and trends in 
relation to ozone and clouds, J. Geophys. Res., 110, D02203, doi:10.1029/2004JD004824, 2005.

Dobson, G. M. B.: A photoelectric spectrophotometer for measuring the amount of atmospheric ozone, Proc. Phys. Soc. London, 43, 324-337, 1931.

Farman, J. C., Gardiner, B. G., and Shanklin, J. D.: Large losses of total ozone in Antarctica reveal seasonal $\mathrm{ClO}_{\mathrm{x}} / \mathrm{NO}_{\mathrm{x}}$ interaction, Nature, 315, 207-210, 1985.

Fioletov, V. E., McArthur, L. J. B., Kerr, J. B., and Wardle, D. I.: Long-term variations of UV-B irradiance over Canada estimated from Brewer observations and derived from ozone and pyranometer measurements, J. Geophys. Res., 106(D19), 23009 23 028, doi:10.1029/2001JD000367, 2001.

Gantner, L., Winkler, P., and Köhler, U.: A method to derive longterm time series and trends of UV-B radiation (1968-1997) from observations at Hohenpeissenberg (Bavaria), J. Geophys. Res., 105(D4), 4879-4888, doi:10.1029/1999JD900907, 2000.

Gleason, J. F., Bhartia, P. K., and Herman, J. R.: Record low global ozone in 1992, Science, 260, 523-526, 1993.

International Agency for Research on Cancer: Solar and Ultraviolet Radiation, Monogr. Eval. Carcinogenic Risks Hum., 55, 336 pp., Geneva, Switzerland, 1992.

International Program on Chemical Safety (IPCS): Ultraviolet Radiation. Environmental Criteria, 160, World Health Organization, Geneva, Switzerland, 1994.

Kaurola, J., Taalas, P., Koskela, T., Borkowski, J., Josefsson, W.: Long-term variations of UV-B doses at three stations in northern Europe, J. Geophys. Res., 105(D16), 20 813-20 820, doi:10.1029/2000JD900258, 2000.

Kazadzis, S., Bais, A., Amiridis, V., Balis, D., Meleti, C., Kouremeti, N., Zerefos, C. S., Rapsomanikis, S., Petrakakis, M., Kelesis, A., Tzoumaka, P., and Kelektsoglou, K.: Nine years of UV aerosol optical depth measurements at Thessaloniki, Greece, Atmos. Chem. Phys., 7, 2091-2101, 2007,

http://www.atmos-chem-phys.net/7/2091/2007/.

Kerr, J. B. and McElroy, C. T.: Total ozone measurements made with the Brewer ozone spectrophotometer during STOIC 1989, J. Geophys. Res., 100(D5), 9225-9230, doi:10.1029/94JD02147, 1995.

Kerr, J. B.: Understanding the factors that effect surface UV radiation, Proc. of SPIE, 5156, 1-14, 2003.

Koepke, P., De Backer, H., Bais, A., Curylo, A., Eerme, K., Feister, U., Johnsen, B., Junk, J., Kazantzidis, A., Krzyscin, J., Lindfors, A., Olseth, J. A., den Outer, P, Pribullova, A., Schmalwieser, A., Slaper, H., Staiger, H., Verdebout, J., Vuilleumier, Komyhr, W. D.: Operations handbook - Ozone observations with a Dobson spectrophotometer, Global Ozone, Research and Monitoring Project Report 6 - WMO, Geneva, Switzerland, 1980.

Krzyścin, J. W.: Statistical reconstruction of daily total ozone over Europe 1950 to 2004, J. Geophys. Res., 113, D07112, doi:10.1029/2007JD008881, 2008.

Kylling, A., Dahlback, A., and Mayer, B.: The effect of clouds and surface albedo on UV irradiances at a high latitude site, Geophys. Res. Lett., 27(9), 1411-1414, doi:10.1029/1999GL011015, 2000.

Lindfors, A., Arola, A., Kaurola, J., Taalas, P., and Svenøe, T.: Long-term erythemal UV doses at Sodankylä estimated using total ozone, sunshine duration and snow depth, J. Geophys. Res., 108(D16), 4518, doi:10.1029/2002JD003325, 2003.
Lindfors, A. and Vuilleumier, L.: Erythemal UV at Davos (Switzerland), 1926-2003, estimated using total ozone, sunshine duration, and snow depth, J. Geophys. Res., 110, D02104, doi:10.1029/2004JD005231, 2005.

Longstreth, I., de Gruijl, F. R., Kripke, M. L., Abseck, S., Arnold, F., Slaper, H., Velders, G., Takizawa, Y., and van der Leun, J. C.: Health risks, J. Photochem. Photobiol. B, 46, 20-33, 1998.

Makowski, K., Wild, M., and Ohmura, A.: Diurnal temperature range over Europe between 1950 and 2005, Atmos. Chem. Phys. Discuss., 8, 7051-7084, 2008,

http://www.atmos-chem-phys-discuss.net/8/7051/2008/.

Matthijsen, J., Slaper, H., and Reinen, H. A. J. M.: Reduction of solar UV by clouds: A comparison between satellite-derived cloud effects and ground-based radiation measurements, J. Geophys. Res., 105(D4), 5069-5080, doi:10.1029/1999JD900937, 2000.

McKenzie, R. L., Madronich, S., and Paulin, K. J.: Effects of snow cover on UV irradiance and surface albedo: A case study, J. Geophys. Res., 103(D22), 28 785-28 792, do:10.1029/98JD02704, 1998.

Moan, J., Dahlback, A., and Setlow, R. B.: Epidemiological support for an hypothesis for melanoma induction indicating a role for UVA radiation, Photchem. Photobiol., 70, 243-247, 1999.

National Radiological Protection Board: Health effects from ultraviolet radiation, Report of an advisory group on non-ionising radiation, Doc. NRP, 13, p. 1, UK, 2002.

Neuwirth, F.: Beziehungen zwischen den Monatswerten der Globalstrahlung und der Sonnenscheindauer in Österreich, Arch. Met. Geoph. Biokl., Ser. B, 26, 171-182, 1978.

Nicolet, M.: On the molecular scattering in the terrestrial atmosphere: an empirical formula for its calculation in the homosphere, Planet. Space Sci., 32, 1467-1468.

Reuder, J. and Koepke, P.: Reconstruction of UV radiation over Southern Germany for the past decades, Meteorol. Z., 14(2), 237-246, 2005.

Ruckstuhl., C., Philipona, R., Behrens, K., Collaud Coen, M., Dürr., B., Heimo, A., Mätzler, C., Nyeki, S., Ohmura, A., Vuilleumier, L., Weller, M., Wehrli, C., and Zelenka, A.: Aerosol and cloud effects on solar brightening and the recent rapid warming, Geophys. Res. Lett., 35, L12708, doi:10.1029/200GL034228, 2008.

Schmalwieser, A. W. and Schauberger, G.: A monitoring network for erythemally-effective solar ultraviolet radiation in Austria: determination of the measuring sites and visualisation of the spatial distribution, Theor. Appl. Climatol., 69, 221-229, 2001.

Schmucki, D. A. and Philipona, R.: Ultraviolet radiation in the alps: The altitude effect, Opt. Eng., 41, 3090-3095, 2002.

Schwander, H., Koepke, P., and Ruggaber, A.: Uncertainties in modeled UV irradiances due to limited accurancy and availability of input data, J. Geophys. Res., 102(D8), 9419-9430, doi:10.1029/97JD00244, 1997.

Schwander, H., Koepke, P., Kaifel, A., and Seckmeyer, G.: Modification of spectral UV irradiance by clouds, J. Geophys. Res., 107(D16), 4319, doi:10.1029/2001JD001297, 2002.

Seckmeyer, G., Mayer, B., Bernhard, G., McKenzie, R. L., Johnston, P. V., Kotkamp, M., Booth, C.R., Lucas, T., Mestechkina, T., Roy, C. R., Gies, H. P., Tomlinson, D.: Geographical differences in the UV measured by intercompared spectroradiometers, Geophys. Res. Lett., 22(14), 1889-1892, doi:10.1029/95GL01352, 1995.

Setlow, R. B.: Wavelengths in sunlight effective in producing skin 
cancer - theoretical analysis, Proc. Nat. Ac. Sci. Am., 71, 9, 3363-3366, 1974.

Simic, S., Weihs, P., Kromp-Kolb, H., Vacek, A., and Laube, W.: Factors affecting changes of spectral UV irradiance at the Sonnblick Observatory (3106 m, Austria), Proc. SPIE, 5979, 597927-1-597927-9, 2005.

Slaper, H., Velders, G. J. M., Daniel, J. S., deGruijl, F. R., and van der Leun, J. C.: Estimates of ozone depletion and skin cancer incidence to examine the Vienna Convention achievements, Nature, 384, 256-258, 1996.

Staehelin, J., Kegel, R., and Harris, N. R.: Trend analysis of the homogenized total ozone series of Arosa (Switzerland), 1929-1996, J. Geophys. Res., 103(D7), 8389-8400, doi:10.1029/97JD03650, 1998a.

Staehelin, J., Renaud, A., Bader, J., McPeters, R., Viatte, P., Hoegger, B., Bugnion, V., Giroud, M., and Schill, H.: Total ozone series at Arosa (Switzerland): Homogenization and data comparison, J. Geophys. Res., 103(D5), 5827-5842, doi:10.1029/97JD02402, 1998b.

Stamnes, K., Tsay, S. C., Wiscombe, W., and Jayaweera, K.: Numerically stable algorithmn for discrete-ordinate-method radiative transfer in multible scattering and emitting layered media, Appl. Opt., 27, 2502-2509, 1988.

Stolarski, R. S., Bloomfield, P., Peters, R. D. M., and Herman, J. R.: Total ozone trends deduced from Nimbus 7 TOMS data, Geophys. Res. Lett., 18(6), 1015-1018, doi:10.1029/91GL01302, 1991.

Tegen, I., Koch D., Lacis, A. A., and Sato, M.: Trends in tropospheric aerosol loads and corresponding impact on direct radiative forcing between 1950 and 1990: A model study, J. Geophys. Res., 105(D22), 26971-26990, doi:10.1029/2000JD900280, 2000.

Thiel, S., Steiner, K., and Seidlitz, H. K.: Modification of global erythemally effective irradiance by clouds, Photchem. Photobiol., 65, 6, 969-973, 1997.

United Nations Environment Program (UNEP): Scientific Assessment on ozone depletion, Global Ozone Research and Monitoring Project, Report No. 47, 498 pp., Geneva, 2002.

United Nations Environment Program (UNEP): Environmental effects of ozone depletion: 1998 assessment, Nairobi, Kenya, 1998.
Vanicek, K., Frei, T., Litynska, Z., and Schmalwieser, A.: UV-index for the public: A guide for publication and interpretation of solar UV index forecasts for the public prepared by the Working Group 4 of the COST-713 action "UVB forecasting", Eur. Coop. Field Sci. Tech. Res., Brussels, 2000.

Weihs, P. and Webb, A.: Accuracy of spectral UV model calculations: 1 - Consideration of uncertainties in input parameters, J. Geophys. Res., 102(D1), 1541-1550, doi:10.1029/96JD01242, 1997.

Weihs, P. and Webb, A.: Accuracy of spectral UV model calculations: 2 - Comparison of UV calculations with measurements, J. Geophys. Res., 102(D1), 1551-1560, doi:10.1029/96JD02621, 1997.

Weihs, P., Simic, S., Laube, W., Mikielewicz, W., Rengarajan, G., and Mandl, G.: Albedo influences on surface UV irradiance at the Sonnblick high mountain Observatory (3106 m altitude), J. Appl. Meteorol., 38, 1599-1610, 1999.

Weihs, P., Lenoble, J., Blumthaler, M., Martin, T., Seckmeyer, G., Philipona, R., De la Casiniere, A., Sergent, C., Gröbner, J., Cabot, T., Masserot, D., Pichler, T., Pougatch, E., Rengarajan, G., Schmucki, D., and Simic S.: Modelling the effect of an inhomogeneous surface albedo on incident UV radiation in mountainous terrain: Determination of an effective surface albedo, Geophys. Res. Lett., 28(16), 3111-3114, doi:10.1029/2001GL012986, 2001.

Weihs, P.: Modelling solar UV radiation in the past: algorithms and input data, Proc. SPIE, 6362, 1-11, 2006.

Woodhead, A. D., Setlow, R. B., and Tanaka, M.: Environmental factors in nonmelanoma and melanoma skin cancer, J. Epidemiol., 9, 102-114, 1999.

World Health Organization (WHO): Environmental Health Criteria 160 - Ultraviolet radiation, 1994.

World Health Organization (WHO): Global Solar UV Index - A practical guide, 2002.

World Health Organization (WHO): Environmental Burden of Disease Series No. 13 - Solar Ultraviolet radiation, 2006. 